\title{
Declarative learning of new real-words in primary and secondary school children: evidence of consolidation over time
}

\author{
Maristella Scorza ${ }^{1}$ - Erika Benassi ${ }^{2}$ - Claudia D. Boni ${ }^{3}$ \\ Chiara Pinotti ${ }^{1}$ - Giacomo Stella ${ }^{1}$ \\ ${ }^{1}$ Department of Education and Human Sciences, University of Modena and Reggio Emilia, Italy \\ ${ }^{2}$ Department of Humanistic Studies, University of Urbino, Italy \\ ${ }^{3}$ Department of Biomedical, Metabolic and Neural Sciences, University of Modena and \\ Reggio Emilia, Italy
}

DOI: http://dx.doi.org/10.7358/neur-2017-022-scor

maristella.scorza@unimore.it

\section{ABSTRACT}

Recent studies found evidence for improvements of declarative memories after a period of offline consolidation. Most of these studies investigated declarative learning using non-words stimuli. Little is known about consolidation effects in the acquisition of phonologically typical real-words in the native-language. The current study compared primary school children with secondary school children in recognition and delayed recall of novel real-words. The delayed recognition and recall tasks were administered both 15 minutes and 24 hours after training. The results revealed high recognition accuracy of the novel real-words after 15-min delay. In contrast, children's recall ability decreased at the first post-training delayed recall but significantly improved when children were re-tested one day later. Better overall performances were observed in secondary school children. The results of our semantic declarative memory task replicate and extend previous findings showing that children's retention of novel semantic-phonological representations is more robust following a period of sleep.

Keywords: Semantic declarative learning; School-aged children; Recognition; Recall; Sleep 


\section{INTRODUCTION}

Complex learning takes longer than a few minutes and requires extensive processing (Chi \& Ohlsson, 2005). For example, learning about new semantic information requires many processes, such as connecting new information with existing knowledge, coordinating different representations, and retrieval abilities (Henderson, Weighall, \& Gaskell, 2013). Many of these learning processes are strictly related with long-term memory (LTM), which have gone so far that the distinction between learning and LTM does not appear clear.

Complex knowledge learning appears to involve two memory systems: procedural memory system and declarative memory system (Squire, Knowlton, \& Musen, 1993). Procedural system is involved in the learning of new sensorimotor and cognitive skills, and other procedures; it is an implicit system because the learning of the procedures and the knowledge itself are not available to conscious access (Ullman, 2004). Declarative system has referred to the learning and storage of explicit knowledge, that is knowledge that is available to conscious awareness (Ullman, 2004); it is involved in the recognition and recall of experiences and semantic information (Tulving \& Schacter, 1990). Research in cognitive neuroscience supports the reality of this distinction between procedural and declarative system (Squire, 2004; Ullman, 2001, 2004).

While the acquisition of procedural knowledge and the development of this memory system has been extensively investigated in children, the declarative learning during the childhood has received scant attention in the literature.

As shown by numerous studies on adults, declarative LTM is composed by two subsystems, namely the episodic memory subsystem, i.e. memory for events in the past, and the semantic memory, which refers to general knowledge and is not related to a specific event (Kopasz et al., 2010). At neuroanatomical and functional level, it is known that declarative LTM depends on medial temporal lobe structures, such as the hippocampal region, entorhinal cortex, perirhinal cortex, and parahippocampal cortex and that this neural complex appears to subserve several related memory functions, including the encoding, consolidation and retrieval of new memories (Squire \& Wixted, 2011). Additionally, anterior frontal cortex is implicated in the consolidation, retrieval of memories, or in the monitoring of that retrieval (Buckner \& Wheeler, 2001; Squire, Genzel, Wixted, \& Morris, 2015). Although the specific brain structures involved in the episodic and semantic subsystems respectively are still not entirely clear, studies on adults concerning semantic dementia and disorders of semantic memory (Snowden, 2002; Vargha-Khadem et al., 1997) found evidence in favour of separate neural circuits.

Focusing on semantic subsystem, the complementary learning systems model (CLS) (McClelland, McNaughton, \& O’Reilly, 1995; Norman \& O’Reilly, 
2003) proposes that new verbal information is initially mediated via a hippocampal network and separately stored from information already held in LTM. This first fast-mapping must allow the child to create an initial representation of a word, but this first mapping is not the end point of word learning (Carey, 1978). In effect, subsequently, offline periods allow the replay of these novel representations and their integration with similar existing words in neocortical areas; in particular, frontal neocortex would have a central role in the consolidation and explicit recall of the new words learnt (Cabeza \& Moscovitch, 2013). Consistent with this model, it is possible to suppose that a good initial rate of learning, tested immediately after exposure to novel verbal information, depends by the first fast-mapping. This first representation may also explain the good performance that adults generally show during recognition task immediately after training (Dumay \& Gaskell, 2007). In effect, recognition ability can be based on an implicit hippocampal representation of the new words and on a sense of familiarity (Brown, Warburton, \& Aggleton, 2010; Hockley \& Consoli, 1999). However, this first mapping is not sufficient for long-term consolidation and free recall of novel words; further processes resulting in the strengthening of neocortical representations are needed (Norman \& O'Reilly, 2003). Studies on adult patients with frontal lobe lesions that exhibited a selective impairment of the free recall ability (Gershberg \& Shimamura, 1995) provide evidence in support of this framework.

Recently, some authors (Brown, Weighall, Henderson, \& Gaskell, 2012; Henderson, Weighall, Brown, \& Gaskell, 2012; Henderson et al., 2013) found similarities in word learning for school-aged children and adults, supporting the CLS model and the hypothesis of a continuity across development of the basic word learning processes (Church \& Fischer, 1998). This hypothesis also implies that offline consolidation should play a role in word learning in children (Brown et al., 2012; Henderson et al., 2013), just as it does in adults (Drosopoulos, Wagner, \& Born, 2005; Gais, Lucas, \& Born, 2006). Brown and colleagues (2012) investigated recognition and recall of non-words in 7and 12-year-old children and found improved recognition of the new nonwords after both short 3-4 hour and longer 24-hour delays. In contrast, recall was initially poor but showed improvements only when children were re-tested 24-hours later. A study (Henderson et al., 2012) found that 7-12-year-old children showed sleep-associated consolidation effects in declarative but not in procedural memory; moreover, following exposure to non-word competitors, children's ability to recognize and recall the non-words improved only after sleep. A further study of Henderson and colleagues (2013) confirmed that offline consolidation is required before new real science words are integrated with the lexicon, in children aged 5-9-years-old. A study of Backhaus, Hoeckesfeld, Born, Hohagen and Junghanns, (2008) found that retention of 
word-pairs in children aged 9-12 years was significantly increased only after an interval of sleep that either followed immediately after learning or that followed after daytime wakefulness, but not after a period of wake-time corresponding in length with the child's habitual sleep time.

The vocabulary learning is a vital component of language acquisition and it is essential that we understand how children acquire new words (Henderson et al., 2012); it is therefore surprising that relatively little work has addressed this issue in primary and secondary school children and that the sleep associated consolidation of semantic declarative knowledge has not been investigated in these children so far.

The current study compared the semantic declarative learning of novel real-words in primary school children with those of secondary school children. An ad hoc measure was created for testing immediate recall, recognition and delayed recall.

First goal of the present study was to examine the performance of primary and secondary school children in an immediate retrieval task which tested the ability to immediately recall new real-words after training. In line with previous developmental studies suggesting that the ability to process and represent lexical information is not complete before 10 years (e.g., Ojima, MatsubaKurita, Nakamura, \& Hagiwara, 2011), we expected better performance in secondary school children compared with primary school children. Moreover, we supposed that both groups significantly improved their performance from the first to the second immediate recall as effect of exposure and the repeated practice (Nicolson \& Fawcett, 2015).

Second goal was to analyze the performance of the two groups in a delayed recognition task. Two delayed recognition phases after training were run, first after 15-min delay and then after 24-hour delay. We expected that both groups recognized a high number of words as early as first recognition test. Moreover, because the recognition of new phonological forms appears already advanced in young children (Church \& Fischer, 1998; Jusczyk \& Aslin, 1995), no differences were expected between the two groups in this ability.

Third goal was to examine the performance of the two groups in a delayed retrieval task. Two delayed recall phases after training were run, first after 15min delay and then after 24-hour delay. Most of the studies on verbal learning in children (Backhaus et al., 2008; Brown et al., 2012; Henderson et al., 2012) have used verbal contents. In our study, we chose to use a task with associated verbal and visual contents, in order to make it more ecological than purely verbal or pictorial tasks. At school or in their everyday life, children are generally exposed to new words and they receive additional semantic information by teachers or adults. For this reason, we were interested in investigating consolidation processes activated by a verbal-visual task. At our knowledge, only one study (Henderson et al., 2013) investigated verbal 
declarative learning using real words associated with additional semantic information in children aged 5-9-years old. Our study for the first time investigated the verbal declarative learning in Italian primary and secondary school children using a more ecological task composed by real words associated with images. Consistent with evidence showing consolidation effects of new words after sleep (Brown et al., 2012; Henderson et al., 2012, 2013), it was predicted that delayed recall of the novel real-words could be poorer than immediate recall, but that recall could improve after a period of offline consolidation.

Moreover, we expected better performance in the secondary school children relative to primary school children in these tasks due to more advanced lexical representation abilities (Ojima et al., 2011).

\section{METHOD}

\subsection{Partecipants}

This study involved fifty monolingual Italian school-aged children: 20 primary school children (group 1) and 30 secondary school children (group 2). The group 1 (10 males, 10 females) had a mean age of 10 years (range 9.2-10.9), while the group 2 (15 males, 15 females) had a mean age of 12 years and 7 months (range 11.0-13.11). Children were recruited from primary and secondary schools (of grade 1) in Reggio Emilia (Northern Italy).

Children were included if they met the following criteria: (a) they spoke Italian as first language; (b) they did not have indication of neurological, visual, or hearing impairment; (c) they did not have indication of intellectual disabilities; (d) they did not have indication of sleep disorders.

The study met ethical guidelines for human subjects' protections, including adherence to the legal requirements of the study country, and received formal approval by the local Research Ethical Committee of the University of Modena and Reggio Emilia.

Parents of the two group of children gave informed written consent for participation in the study, data analysis, and data publication.

\subsection{Procedure}

In order to assess the semantic learning of novel real-words in the two groups, an ad hoc task was created. It was composed of a list of 20 real-words each associated with an image that represented the meaning of the word (see Appendix 1). The 20 real-words met the following criteria: they were Italian real-words; they 
referred to objects of different semantic categories (e.g., animals, plants); they were very low frequency words in Italian speech ("new" words) and very low imageability words (De Mauro, Mancini, Vedovelli, \& Voghera, 1993); they were two- and three-syllable words and characterized by different first phoneme.

Further 30 real-words were chosen as competitors in the recognition task. The choice of these 30 competitor words respected the same criteria followed for the 20 target words.

Participants were tested individually in a quiet area of their school the day 1 and day 2. Before training (or exposure phase) the instructions were explained and an example was given. No feedback was provided during the recognition and recall tasks. Responses were transcribed and scored for accuracy.

The day 2, to all children asked for information about the quality of their sleep, to verify that they slept as normally would.

Appendix 1. List of the 20 target words and 30 competitor words used on the semantic declarative learning task

\begin{tabular}{ll}
\hline Target words & \multicolumn{1}{c}{ Italian real-words } \\
& Graviola, Pialla, Alpaca, Liuto, Frattone, Umbonia, \\
& Marra, Batacchio, Gerboa, Tiara, Crivello, Galena, \\
& Rafano, Beuta \\
Competitor words & Ruta, Coledoco, Verro, Diploe, Zagaglia, Faretra, \\
& Tripode, Anatasio, Marrancio, Cicloide, Diottra, \\
& Viburno, Borragine, Erpice, Daga, Cotonaria, Inula, \\
& Starna, Ottante, Nelumbo, Gerbera, Bitta, Livella, \\
& Acerola, Fiocina, Scalmo, Uria, Nassa, Acetabolo, \\
& Pagaia \\
\hline
\end{tabular}

\subsubsection{Training and immediate recall}

Each child participated in two training sessions. Each training session was characterized by five sequential acoustic-visual presentations (word + image) of the target words. All target stimuli were presented at a comfortable listening level through vocal synthesizer and the images were presented for $3 \mathrm{~s}$ each using PowerPoint software. The child sat directly in front of the computer.

At the end of the first training session, first immediate recall task was tested (First IR). The child was asked to recall orally the words while he/she 
was watching the images on the computer. At the end of the second training session, children were again asked to recall the words (Second IR) using the same recall procedure as during the First IR. A break of 5 minutes was included between the two training sessions to maximize the child's attention.

\subsubsection{Delayed recall - day 1}

The child was tested in a delayed recall task (DRecall day 1) either later the same day following a 15-min delay. The child was asked to observe the target images on the computer and orally recall the words learnt during the exposure phase.

\subsubsection{Delayed recognition - day 1}

The DRecall day 1 was followed by a delayed recognition task (DRecogn. day 1), after a break of 15 minutes. The experimenter read to the child a list of 50 words including the 20 target words and 30 competitor words. For each word listened, the child was asked to say "YES" if for he/she the word was a target word or say "NO" if it was not.

\subsubsection{Delayed recall - day 2}

One day later approximately 24 hours after the DRecogn. day 1, the child was re-tested in a delayed recall task (DRecall day 2). The child asked to observe the target images on the computer and orally recall the words learnt during the exposure phase, using the same recall procedure as during the DRecall day 1.

\subsubsection{Delayed recognition - day 2}

After a break of 15 minutes, the child was re-tested in a delayed recognition task (DRecogn. day 2). This task was run using the same recognition procedure as during the DRecogn. day 1.

\section{RESULTS}

Descriptive data for immediate recall, delayed recognition and delayed recall tasks in primary and secondary school children are presented in Table 1 . To evaluate potential differences in the semantic learning tasks between the two groups, three repeated measures analyses of variance (ANOVAs) were conducted. All statistical analyses were carried out using SPSS 21.0 for Windows with an alpha level of 0.05. Prior to conducting analyses, data were checked for violation of assumptions using Kolmogorov-Smirnov, Levene tests and Mauchly tests. 
Table1. Descriptive data (mean, standard deviation and range) and ANOVA betweensubjects-values ( $p$ and Cohen's $d$ ) from the accuracy scores for the immediate recall tasks (First $I R$, Second IR), delayed recognition tasks (DRecogn. day 1, DRecogn. day 2) and delayed recall tasks (DRecall day 1, DRecall day 2) in the primary and secondary school children

\begin{tabular}{lccccccccc}
\hline & \multicolumn{3}{c}{$\begin{array}{c}\text { Primary school } \\
(n=20)\end{array}$} & \multicolumn{3}{c}{$\begin{array}{c}\text { Secondary school } \\
(n=30)\end{array}$} & \multicolumn{2}{c}{ ANOVA } \\
& $M$ & $S D$ & range & $M$ & $S D$ & range & $p$ & $d$ \\
First IR & 8.35 & 4.51 & $0-15$ & 11.20 & 3.60 & $4-18$ & .017 & .68 \\
Second IR & 12.55 & 5.06 & $3-19$ & 15.67 & 4.05 & $7-20$ & .020 & .66 \\
Recogn. day 1 & 18.40 & 1.96 & $13-20$ & 18.63 & 1.61 & $14-20$ & .647 & .07 \\
Recogn. day 2 & 18.65 & 1.81 & $12-20$ & 18.87 & 1.72 & $12-20$ & .671 & .07 \\
DR day 1 & 11.85 & 4.69 & $1-18$ & 14.13 & 4.34 & $6-20$ & .084 & .41 \\
DR day 2 & 12.20 & 5.11 & $3-19$ & 14.93 & 4.24 & $7-20$ & .045 & .52 \\
\hline Significant results are in bold & & & & & & &
\end{tabular}

The first RM-ANOVA was conducted to examine the children's performance on immediate recall tasks, with participant group (primary school children, secondary school children) as a between-subjects variable and type of task (First IR, Second IR) as a within-subjects variable. The number of correctly recalled words served as the dependent measure. A significant difference was observed for participant group, $\mathrm{F}(1,48)=6.35, \mathrm{p}=.015, \mathrm{~d}=$ .70 , with significantly greater accuracy by the secondary school children than by the primary school children (First IR, $\mathrm{p}=.017$; Second IR, $\mathrm{p}=.020$ ). A significant effect was also seen for type of task, $\mathrm{F}(1,48)=194.30, \mathrm{p}<.001, \mathrm{~d}=$ 1.00 , with significantly greater accuracy on the Second IR $(M=14.42, S D=$ 4.70) than accuracy on the First IR $(M=10.06, S D=4.19)$. The participant group $\mathrm{x}$ type of task interaction was not significant. 


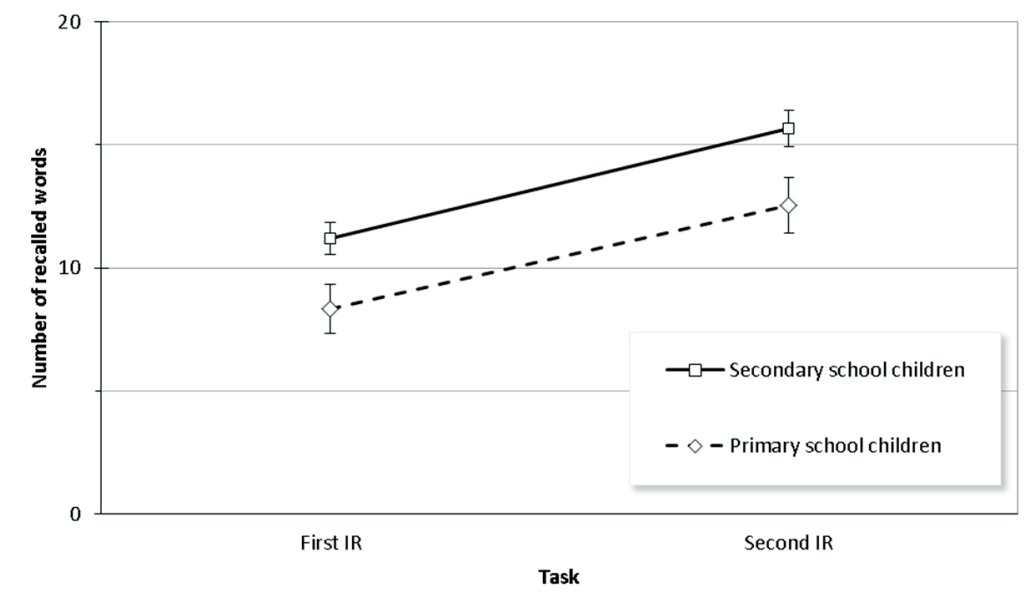

Figure 1. Number of correctly recalled words on the First IR and Second IR in the primary and secondary school children

The second RM-ANOVA was conducted to analyze how the children's performance on delayed recognition tasks changed relative to the Second IR, with participant group as a between-subjects variable and type of task (Second IR, DRecogn. day 1, DRecogn. day 2) as a within-subjects variable. The number of correctly recognized words served as the dependent measure. The participant group was not significant. A significant effect was observed for type of task, $\mathrm{F}(1,48)=70.70, \mathrm{p}=<.001, \mathrm{~d}=1.00$. Post-hoc testing revealed that accuracy on the Second IR was significantly lower than accuracy on both the DRecogn. day $1(\mathrm{M}=18.54, \mathrm{SD}=1.74 ; \mathrm{p}<.001)$ and the DRecogn. day $2(\mathrm{M}$ $=18.78, \mathrm{SD}=1.74 ; \mathrm{p}<.001)$. No significant difference was found between the accuracy on the DRecogn. day 1 and DRecogn. day 2. The participant group $\mathrm{x}$ type of task interaction was significant, $\mathrm{F}(1,48)=6.88, \mathrm{p}=.012, \mathrm{~d}=.73$. 


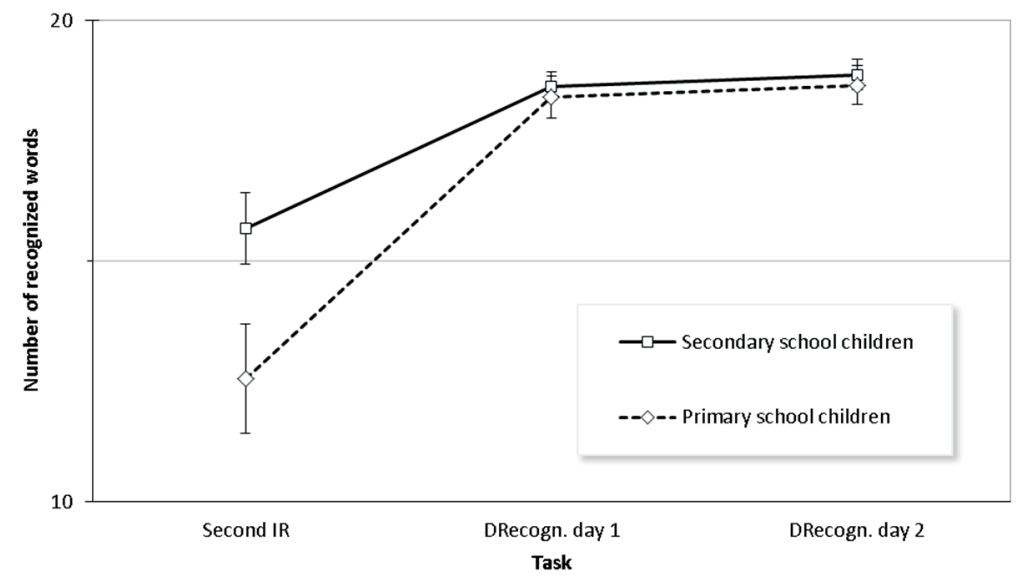

Figure 2. Number of correctly recognized words on the DRecogn. day 1 and Recogn. day 2 , relative to the Second IR, in the primary and secondary school children

The third RM-ANOVA was conducted to examine how the children's performance on delayed recall tasks changed relative to the Second IR, with participant group as a between-subjects variable and type of task (Second IR, DRecall day 1, DRecall day 2) as a within-subjects variable. The number of correctly recall words served as the dependent measure. A significant difference was observed for participant group $\mathrm{F}(1,48)=4.48, \mathrm{p}=.040, \mathrm{~d}=.55$, with significantly greater accuracy by the secondary school children than by the primary school children on the DRecall day $2(\mathrm{p}=.045)$; no significant difference was found between the two groups on DRecall day 1. A significant effect was also seen for type of task, $\mathrm{F}(1,48)=6.47, \mathrm{p}=.014, \mathrm{~d}=.70$. Post-hoc testing revealed that accuracy on the Second IR was significantly higher than accuracy on both the DRecall day $1(\mathrm{M}=13.22, \mathrm{SD}=4.58 ; \mathrm{p}<.001)$ and the DRecall day $2(\mathrm{M}=13.84, \mathrm{SD}=4.75 ; \mathrm{p}=.043)$. The accuracy on the DRecall day 2 was significantly higher than accuracy on the DRecall day $1(\mathrm{p}=.021)$. The participant group $\mathrm{x}$ type of task interaction was not significant. 


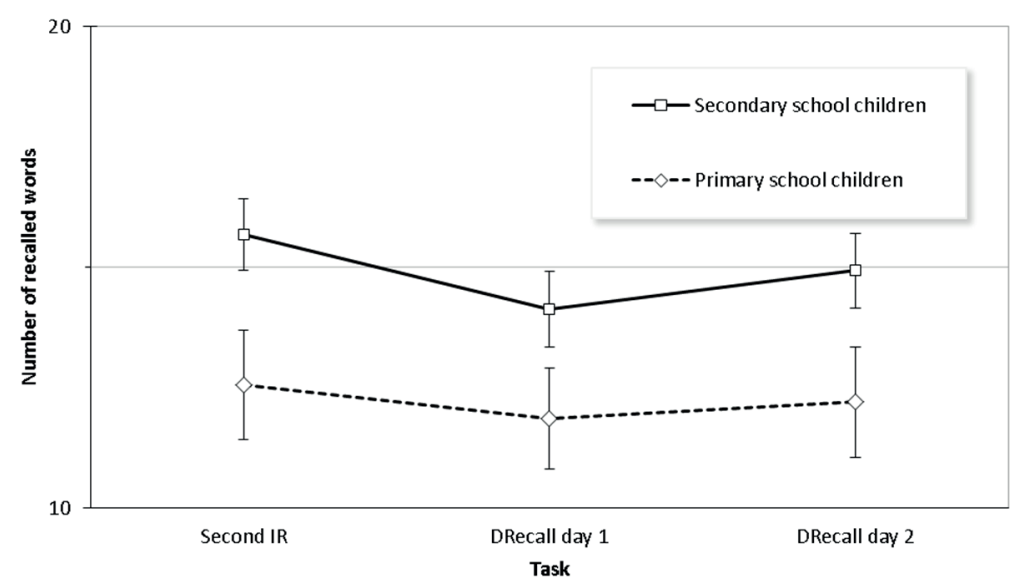

Figure 3. Number of correctly recalled words on the DRecall day 1 and DRecall day 2, relative to the Second IR, in the primary and secondary school children

\section{DISCUSSION}

The first major finding of this study concerns the differences that we found between the two groups of children in the immediate recall tasks. The secondary school children showed more advanced performances than primary school children both at first and second immediate recall. DiGiulio, Seidenberg, O'Leary, and Raz (1994), investigating the declarative and procedural memory development in 8- and 12-year-old children, found that procedural learning abilities established around the first years of primary school, while the declarative learning abilities continued to enhance during the secondary school period. This is consistent with our findings suggesting that the children's ability to learn novel spoken words is still very high in this developmental phase. Additionally, we found in both groups a significant improvement between the first and the second immediate recall. Previous research, focusing on the immediate aspects of word learning in children, found rapid learning of novel phonological forms (Church \& Fischer, 1998; Spiegel \& Halberda, 2011). Consistent with this research and with the first fast-mapping theory (Carey, 1978), our results showed that both the primary and secondary school children demonstrated rapid semantic learning abilities, after only minimal exposure.

With regard to the second aim, our hypothesis appears confirmed. The both groups showed to accurately recognize the novel real-words after both 
short 15-min and longer 24-hour delay. Their high performance in both delayed recognition tasks was likely due to a ceiling effect. In adult studies, recognition immediately after training is typically near-ceiling (Dumay \& Gaskell, 2007). This finding provides evidence of this ceiling effect in delayed recognition phases in school children. Moreover, no differences were found between the two groups; the primary school children showed comparable recognition abilities with those of the secondary school children. This finding is consistent with studies showing that by around 10 years of age word recognition and lexical representations appear to be adult-like (Ojima et al., 2011). Therefore, our study highlights adult-like abilities to form stable memory traces on word learning as early as primary school-aged children.

A third interesting contribution of the present study has to do with the delayed recall tasks. In contrast with the improvement on delayed recognition task of day 1 , the number of correctly recall words on the delayed recall of day 1 was significantly lower relative to the second immediate recall, in both groups. This is in line with the study of Brown and colleagues (2012) that found a poor recall of nonwords in 7- and 12-year old children after a 3-4 hour delay from the exposure phase. Our study highlighted a similar pattern on the recall of novel low frequency Italian words. As reported by Brown and colleagues (2012), one explanation may be that explicit recall of novel words requires retention and retrieval of highlyspecified phonological representations, whereas simple recognition of novel words may simply involve listening preferentially for a familiar acoustic form.

Interestingly, a significant improvement on recall task was observed 24 hours later, in both groups. The delayed recall ability showed to increase not after a short period whilst awake, but only over a longer period including sleep. Our results are consistent with the increasing literature concerning close relationships between sleep and memory in children and teens (for a review, Kopasz at al., 2010). However, our results partially conflicted with other studies that found significantly higher accuracy on post-sleep delayed recall task with respect to post-learning immediate recall (Backhaus et al., 2008; Brown et al., 2012; Henderson et al., 2013). In fact, we found that the number of correctly recalled words on the recall of day 2 significantly increased with respect to the recall of day 1 , but it kept lower than the number of recalled words on the second immediate recall. Additionally, Henderson and colleagues (2013) found that children who were exposed to semantic information about the target words during training showed further improvements in recall after one week and outperformed the children who were not exposed to this information. These findings seem to contrast with our results. The performance increase on post-sleep delayed recall task of our primary and secondary school children did not appear as significant as that of the children exposed to semantic information in the Henderson and colleagues' study. For

Neuropsychological Trends - 22/2017

http://www.ledonline.it/neuropsychologicaltrends/ 
this reason, we can speculate that the visual stimuli associated with verbal stimuli used in our study do not strongly facilitate the delayed recall. However, because our experimental design did not include a control condition where children underwent a learning task without supporting images, these our suppositions remain open. Further research should be conducted to confirm our results and analyze whether there may be differences between children that undergo a learning task with supporting images and without them. Despite this limitation of the study, the significant improvement that we observed between the two delayed recall tasks appears to bring evidence of the role of sleep in the stabilization of novel semantic representations. As other authors have highlighted in children and infants (Wilhelm, Diekelmann, \& Born, 2008), a greater capacity to learn and to memorize coincides with longer and deeper sleep. Our study suggests that the transformation in memory that occurs during sleep has the consequence of enhancing new semantic representations without additional training in primary and secondary school children.

Comparing the delayed retrieval performances of the two groups, no significant differences were found on the delayed recall task of day 1, although the secondary school children obtained higher accuracy scores than primary school children. Instead, significant differences emerged between the two groups on the delayed recall task of day 2, with a significant higher performance in secondary school children relative to primary school children. The general better performance in secondary school children at the delayed test points supports the hypothesis of more advanced semantic long-term storage capacities and retrieval strategies in older children relative to younger children (DiGiulio et al., 1994).

\section{CONCLUSION}

The present study differs from previous studies that examined recognition and recall of fictitious non-words or word-pairs, because it focused on semantic declarative learning of real very low frequent Italian words and on differences between primary and secondary school children in this type of long-term learning. Thus, our results replicate and extend previous findings providing further evidence in support of the CLS model and the role of offline consolidation on the formation of novel semantic representations in primary and secondary children. In effect, the findings reported here show a rapid semantic learning of novel real-words and high recognition abilities already after few minutes from the exposure phase, demonstrating good first fastmapping abilities in both groups of children, with better overall accuracy scores 
in secondary school children. The delayed recall ability, while decreasing after few minutes from the exposure, it appears to increase again 24 hours after training, in both groups; thus, children's semantic memories appear to benefit from offline consolidation including a sleep period.

In the light of these considerations, it is possible to suppose that repeated exposure to new words and repetitions of target words may promote new meaning learning in school-aged children, as suggested by other studies regarding the infants and young children's lexical development (Benassi, Guarini, Savini, Iverson, Caselli, et al., in review; Rescorla, Frigerio, Sali, Spataro, \& Longobardi, 2014), but that long-term semantic consolidations mainly depend by sleep (Brown et al., 2012). However, this conclusion should be treated with caution, because the design used in this study cannot separate the roles of sleep and time in stabilizing new semantic knowledge and also because significant improvements on post-sleep delayed recall task relative to the post-learning immediate recall did not found. A future step would be to examine if children's ability to explicitly recall new semantic knowledge improves over a one week period. Additionally, the present findings need to be validated with further studies that monitor the sleep qualities between shortand long-term recalls and with evidence concerning precise aspects of sleep that are involved.

There are some important clinical implications of these findings for children with neurodevelopmental disorders associated with poor sleep, such as dyslexia (Carotenuto, Esposito, Cortese, Laino, \& Verrotti, 2016; Smith \& Henderson, 2016). Deficits have been found in tasks that probe long-term common knowledge, such as in object naming tests, in these children; lexical knowledge remains largely unaffected in the disorder, as evidenced by studies of receptive vocabulary (Richardson, Thomson, Scott, \& Goswami, 2004; Swan \& Goswami, 1997). By contrast, recent studies highlighted procedural system impairments versus unimpaired performances on declarative learning tasks in children with dyslexia (Ullman \& Pullman, 2015; Vicari, Marotta, Menghini, Molinari, \& Petrosini, 2003). However, relatively little is known about postsleep declarative consolidation processes in these children. Future research will be needed to determinate if poor sleep habits are associated with difficulty in the formation of stabile new semantic representations in this clinical population.

Vocabulary acquisition is crucial for academic development. More research is also needed on the environmental factors that can promote longterm semantic consolidations both in typically and atypically developing school-aged children. For example, future investigations have to consider the combined influence of teaching strategies, semantic learning processes and sleep in understanding ongoing knowledge development in these children. 


\section{REFERENCES}

Backhaus, J., Hoeckesfeld, R., Born, J., Hohagen, F., \& Junghanns, K. (2008). Immediate as well as delayed post learning sleep but not wakefulness enhances declarative memory consolidation in children. Neurobiology of Learning and Memory, 89(1), 76-80.

Benassi, E., Guarini, A., Savini, S., Iverson, J. M., Caselli, M. C., et al. (in review). Maternal responses and development of communication skills in extremely preterm infants. First Language.

Brown, M. W., Warburton, E. C., \& Aggleton, J. P. (2010). Recognition memory: Material, processes, and substrates. Hippocampus, 20(11), 1228-1244.

Brown, H., Weighall, A., Henderson, L. M., \& Gaskell, M. G. (2012). Enhanced recognition and recall of new words in 7- and 12-year old children following a period of offline consolidation. Journal of Experimental Child Psychology, 112(1), 56-72.

Buckner, R. L., \& Wheeler, M. E. (2001). The cognitive neuroscience of remembering. Nature Reviews Neuroscience, 2(9), 624-634.

Cabeza, R., \& Moscovitch, M. (2013). Memory systems, processing modes, and components: Functional neuroimaging evidence. Perspectives on Psychological Science, 8(1), 49-55.

Carey, S. (1978). The child as a word learner. In M. Halle, J. Bresnan \& A. Miller (Ed.), Linguistic Theory and Psychological Reality (pp. 264-293). Cambridge, MA: MIT Press.

Carotenuto, M., Esposito, M., Cortese, S., Laino, D., \& Verrotti A. (2016). Children with developmental dyslexia showed greater sleep disturbances than controls including problems initiating and maintaining sleep. Acta Paediatrica, 105(9), 1079-1082.

Chi, M. T .H., \& Ohlsson, S. (2005). Complex declarative learning. In K. J. Holyoak \& R. G. Morrison (Ed.), The Cambridge Handbook of Thinking and Reasoning (pp. 371-399). New York: Cambridge University Press.

Church, B. A., \& Fischer, C. (1998). Long-term auditory word priming in preschoolers: Implicit memory support for language acquisition. Journal of Memory and Language, 39(4), 523-542.

De Mauro, T., Mancini, F., Vedovelli, M., \& Voghera, M. (1993). Lessico di frequenza dell'italiano parlato (LIP). Milano: EtasLibri.

DiGiulio, D. V., Seidenberg, M., O’Leary, D. S., \& Raz, N. (1994). Procedural and declarative memory: A developmental study. Brain and Cognition, 25(1), 79-91.

Drosopoulos, S., Wagner, U., \& Born, J. (2005). Sleep enhances explicit recollection in recognition memory. Learning \& Memory, 12(1), 44-51. 
Dumay, N., \& Gaskell, M. G. (2007). Sleep-associated changes in the mental representation of spoken words. Psychological Science, 18(1), 35-39.

Gais, S., Lucas, B., \& Born, J. (2006). Sleep after learning aids memory recall. Learning \& Memory, 13(3), 259-62.

Gershberg, F. B., \& Shimamura, A. P. (1995) Impaired use of strategies in free recall following frontal lobe damage. Neuropsychologia, 13(10), 1305-1333.

Henderson, L. M., Weighall, A., Brown, H., \& Gaskell, M. G. (2012). Consolidation of vocabulary is associated with sleep in children. Developmental Science, 15(5), 674-687.

Henderson, L. M., Weighall, A., \& Gaskell, M. G. (2013). Learning new vocabulary in childhood: Effects of semantic training on lexical consolidation and integration. Journal of Experimental Child Psychology, 116(3), 572-592.

Hockley, W. E., \& Consoli, A. (1999). Familiarity and recollection in item and associative recognition. Memory and Cognition, 27(4), 657-664.

Jusczyk, P. W., \& Aslin, R. N. (1995). Infants' detection of the sounds patterns of words in fluent speech. Cognitive Psychology, 29(1), 1-23.

Kopasz, M., Loessl, B., Hornyak, M., Riemann, D., Nissen, C., Piosczyk, H., \& Voderholzer, U. (2010). Sleep and memory in healthy children and adolescents - A critical review. Sleep Medicine Reviews, 14(3), 167-177.

McClelland, J. L., McNaughton, B. L., \& O'Reilly, R. C. (1995). Why there are complementary learning-systems in the hippocampus and neocortex: Insights from the successes and failures of connectionist models of learning and memory. Psychological Review, 102(3), 419-457.

Nicolson, R. I., \& Fawcett, A. J. (2015). Motor Sequence Learning in Dyslexia: Is consolidation the Key? BPA-Applied Psychology Bullettin, 64(273), 5-15.

Norman, K. A., \& O'Reilly, R. C. (2003). Modeling hippocampal and neocortical contributions to recognition memory: A complementary-learning-systems approach. Psychological Review, 110(4), 611-646.

Ojima, S., Matsuba-Kurita, H., Nakamura, N., \& Hagiwara, H. (2011). The acceleration of spoken-word processing in children's native-language acquisition: an ERP cohort study. Neuropsychologia, 49(5), 790-799.

Rescorla, L., Frigerio, A., Sali, M. E., Spataro, P., \& Longobardi, E. (2014). Typical and Delayed Lexical Development in Italian. Journal of Speech, Language, and Hearing Research, 57(5), 1792-1803.

Richardson, U., Thomson, J. M., Scott, S. K., \& Goswami, U. (2004). Auditory processing skills and phonological representation in dyslexic children. Dyslexia, 10(3), 215-233. 
Smith, F. R. H., \& Henderson, L. M. (2016). Sleep problems in children with dyslexia: understanding the role of sleep in neurocognitive development through the lens of developmental disorders. Acta Paediatrica, 105(9), 999-1000.

Snowden, J. (2002). Disorders of semantic memory. In A.D. Baddeley, M. D. Kopelman \& B. A. Wilson (Ed.), The Handbook of Memory Disorders (2th ed.) (pp. 293-314.) West Sussex: John Wiley \& Sons, Ltd.

Spiegel, C., \& Halberda, J. (2011). Rapid fast-mapping abilities in 2-year-olds. Journal of Experimental Child Psychology, 109(1),132-140.

Squire, L. R. (2004). Memory systems of the brain: A brief history and current perspective. Neurobiology of Learning and Memory, 82(3), 171-177.

Squire, L. R., Genzel, L., Wixted, J. T., \& Morris, R. G. (2015). Memory consolidation. Cold Spring Harbor Perspectives in Biology, 7(8), 1-21.

Squire, L. R., Knowlton, B., \& Musen, G. (1993). The structure and organization of memory. Annual Review of Psychology, 44(1), 453-495.

Squire, L.R., \& Wixted J. T. (2011). The cognitive neuroscience of human memory since H.M. Annual Review of Neuroscience, 34(1), 259-288.

Swan, D., \& Goswami U. (1997). Picture naming deficits in developmental dyslexia: the phonological representations hypothesis. Brain and Language, 56(3), 334-353.

Tulving, E., \& Schacter, D. L. (1990). Priming and human memory systems. Science, 247(4940), 301-306.

Ullman, M. T. (2001). The neural basis of lexicon and grammar in first and second language: The declarative/procedural model. Bilingualism: Language and Cognition, 4(1), 105-122.

Ullman, M. T. (2004). Contributions of memory circuits to language: The declarative/procedural model. Cognition, 92(1-2), 231-270.

Ullman, M. T., \& Pullman, M. Y. (2015). A compensatory role for declarative memory in neurodevelopmental disorders. Neuroscience and Biobehavioral Reviews, 51, $205-222$.

Vargha-Khadem, F., Gadian, D. G., Watkins, K. E., Connelly, A., Van Paesschen, W., \& Mishkin, M. (1997). Differential Effects of Early Hippocampal Pathology on Episodic and Semantic Memory. Science, 277(5324), 376-380.

Vicari, S., Marotta, L., Menghini, D., Molinari, M., \& Petrosini, L. (2003). Implicit learning deficit in children with developmental dyslexia. Neuropsychologia, 41(1), 108-114.

Wilhelm, I., Diekelmann, S., \& Born, J. (2008). Sleep in children improves memory performance on declarative but not procedural tasks. Learning \& Memory, 15(5), 373-377. 
